\title{
Hábitos Dietéticos de Pacientes com Câncer Colorretal em Fase Pós-operatória
}

\author{
Dietary Habits of Post-operative Colorectal Cancer Patients
}

\author{
Renata Costa Fortes', Viviane Lacorte Recôva², Andresa Lima Meloº , Maria Rita Carvalho Garbi Novaes ${ }^{3}$
}

\section{Resumo}

Introdução: Estilo de vida é fator de risco para o câncer colorretal, pois a interação entre dieta inadequada, alcoolismo, tabagismo, obesidade e inatividade física podem levar ao seu desenvolvimento. Objetivo: Analisar os hábitos dietéticos de portadores de câncer colorretal em fase pós-operatória. Metodologia: Estudo transversal descritivo. Amostra constituída por 70 pacientes com câncer colorretal, atendidos no Ambulatório de Proctologia do Hospital de Base do Distrito Federal. Foram coletados dados antropométricos, dietéticos e de hábitos de vida. Resultados: Os pacientes assistidos, 28 homens e 42 mulheres, idade média de 58,30 anos, praticavam alguma atividade física: 71,43\%. Eram tabagistas 8,60\% e ex-tabagistas 24,30\%. Consumiam bebida alcoólica 11,40\%. Quanto aos hábitos dietéticos: $87,10 \%$ consumiam de cinco a nove porções/dia de cereais, pães, raízes e tubérculos; $7,10 \%$, de três a cinco porções/dia de frutas; $2,90 \%$, de quatro a cinco porções/dia de hortaliças; $28,60 \%$, uma porção/dia de leguminosas; $15,70 \%$, três porçôes/dia de leite e derivados; $61,40 \%$, de uma a duas porções/dia de carnes e ovos; $31,40 \%$, de uma a duas porçôes/dia de doces e açúcares; $8,60 \%, \geq 25 \mathrm{~g} /$ dia de fibras; $11,40 \%, \geq 2$ litros/dia de água e, $70 \%, \geq 2$ xícaras/dia de café. Quanto ao preparo dos alimentos, 72,90\% usavam gordura vegetal, e $22,90 \%$ animal; $12,90 \%$ usavam condimentos industrializados, $72,90 \%$ naturais, e $12,90 \%$ usavam ambos. Conclusão: Foi observada ingestão dietética precária da maioria dos fatores protetores contra o câncer colorretal. Os resultados sugerem a necessidade da realização de programas educacionais multidisciplinares com o intuito de orientar os pacientes à melhoria da qualidade de vida com reforço dos hábitos de vida saudáveis.

Palavras-chave: Dieta, Câncer colorretal, Hábitos de vida 


\section{INTRODUÇÃO}

O câncer colorretal, uma das neoplasias malignas mais freqüentes no ocidente, é considerado a quarta causa mais comum de câncer no mundo ${ }^{1}$ e a terceira causa de incidência e mortalidade em ambos os sexos nos Estados Unidos $^{2}$. No Brasil, ele representa a quinta neoplasia mais diagnosticada e a quarta causa de óbitos, sendo que cerca de metade dos pacientes morre em menos de cinco anos, após o tratamento ${ }^{3}$.

O Instituto Nacional de Câncer estimou para 2006, no Brasil, 11.390 casos novos de câncer colorretal no sexo masculino (12 casos novos a cada 100 mil homens) e 13.970 casos no sexo feminino ( 15 casos novos a cada 100 mil mulheres) ${ }^{1}$.

A incidência do câncer colorretal apresenta padrōes bastante diferenciados entre as distintas regiōes mundiais, o que sugere uma forte influência de fatores locais. Essa distinção pode ser observada de forma semelhante no Brasil, onde as regiōes Sul e Sudeste apresentam elevada incidência dessa neoplasia em relação às regiōes Norte e Nordeste, possivelmente em conseqüência de diferenças nos padrões dietéticos e no desenvolvimento socioeconômico .

Mais de 90\% dos cânceres de cólon e reto ocorrem em indivíduos com idade superior a 50 anos, e $75 \%$ atingem indivíduos sem outros fatores de risco além da idade. As síndromes de cânceres colorretais hereditários, polipose adenomatosa familiar e síndrome de Lynch representam somente $1 \%$ a $3 \%$ dos casos, sendo que $10 \%$ a $30 \%$ dos casos são secundários à predisposição hereditária 5 .

O desenvolvimento de várias formas de câncer resulta da interação entre fatores endógenos e ambientais, destacando-se a dieta que, quando inadequada, representa cerca de 35\% dos diversos tipos de câncer. Outros fatores incluem o etilismo, o tabagismo, a obesidade, a inatividade física e a exposição a determinados agentes viróticos, bacterianos e parasitários, além do contato freqüente com algumas substâncias carcinogênicas ${ }^{6}$.

Este estudo teve como objetivo principal analisar os hábitos dietéticos de portadores de câncer colorretal em fase pós-operatória, atendidos no Ambulatório de Proctologia do Hospital de Base do Distrito Federal (HBDF).

\section{METODOLOGIA}

\section{Delimitação do ESTUdo}

Realizou-se um estudo transversal, descritivo, com uma amostra constituída por 70 pacientes (28 homens e 42 mulheres), portadores de câncer colorretal, estádios
I ( $\mathrm{n}=12)$, II $(\mathrm{n}=20)$ e III $(\mathrm{n}=38)$, idade média de 58,30 anos, índice de massa corpórea (IMC) médio $=24,65 \mathrm{~kg} /$ $\mathrm{m}^{2}$, em fase pós-operatória, atendidos no Ambulatório de Proctologia do Hospital de Base do Distrito Federal, no período de novembro de 2005 a maio de 2006.

Os pacientes foram selecionados de acordo com os seguintes critérios de inclusão: portadores de câncer colorretal em fase pós-operatória, de três meses a dois anos de intervenção cirúrgica, idade superior a 20 anos, que aceitaram participar do estudo e que assinaram o Termo de Consentimento Livre e Esclarecido. Os critérios de exclusão foram: gestantes, lactantes, acamados, deficientes físicos, portadores de outras doenças crônicas não-transmissíveis e em processo de metástase.

O protocolo foi aprovado pelo Comitê de Ética em Pesquisa da Secretaria de Estado de Saúde do Distrito Federal sob o no 051/2004.

Posteriormente, cada paciente recebeu o resultado da sua avaliação antropométrica, além de um acompanhamento nutricional por um período de seis meses e encaminhamento para outro profissional da área de saúde, sempre que necessário.

\section{Dados ANTROPOMÉtRICOS}

A coleta das variáveis antropométricas (peso e estatura) foi realizada por nutricionistas e acadêmicos de medicina e nutrição previamente treinados, com o intuito de padronizar a coleta de dados durante a aferição dessas medidas (técnicas para a mensuração de peso e altura) $)^{7}$.

Para a aferição do peso, todos os pacientes posicionaram-se em pé, em cima dos sensores da balança, descalços, com os bolsos vazios e com roupas leves ${ }^{7}$. O peso foi aferido uma única vez em quilograma $(\mathrm{kg})$, usando uma balança digital Plenna ${ }^{\circledR}$ - Resolve, modelo MEA-02500, com capacidade para $150 \mathrm{~kg}$ e variação de $0,1 \mathrm{~kg}$, devidamente calibrada.

Para a medida da estatura, os pacientes ficaram de pé, descalços, em posição ortostática, com o corpo erguido em extensão máxima, cabeça ereta, olhando para a frente, em posição de Frankfört, com as costas e a parte posterior dos joelhos encostados à parede e os pés juntos ${ }^{7}$. A estatura foi aferida uma única vez em centímetros $(\mathrm{cm})$, com fita métrica inelástica de $150 \mathrm{~cm}$ de comprimento, afixada em parede plana, sem rodapé, a $50 \mathrm{~cm}$ do chão. Colocou-se um esquadro na parte superior da cabeça, obtendo-se dessa forma a medida com precisão de $0,1 \mathrm{~cm}$.

A partir da aferição dessas variáveis antropométricas, obteve-se o indicador do estado nutricional, IMC ou índice de Quetelet, calculado pela divisão do peso em $\mathrm{kg}$ pela estatura, em metros, ao quadrado $\left(\mathrm{m}^{2}\right)^{7}$. 
Para a classificação do estado nutricional dos pacientes adultos e idosos, segundo o índice de massa corporal, usou-se o valor de IMC $<18,5 \mathrm{~kg} / \mathrm{m}^{2}$ para se caracterizar magreza; $\geq 18,5 \mathrm{~kg} / \mathrm{m}^{2}$ e $<25 \mathrm{~kg} / \mathrm{m}^{2}$, eutrofia; $\geq 25 \mathrm{~kg} / \mathrm{m}^{2}$ e $<30 \mathrm{~kg} / \mathrm{m}^{2}$, sobrepeso; e $\geq 30 \mathrm{~kg} / \mathrm{m}^{2}$ obesidade, de acordo com a classificação sugerida pela Organização Mundial de Saúde ${ }^{8}$. Posteriormente, para avaliar o estado nutricional de idosos ( $\geq 60$ anos), analisou-se separadamente o IMC, considerando-se o valor de IMC $<22 \mathrm{~kg} / \mathrm{m}^{2}$ para se caracterizar magreza; $\geq 22 \mathrm{~kg} / \mathrm{m}^{2}$ e $<27 \mathrm{~kg} / \mathrm{m}^{2}$, eutrofia; e $\geq 27 \mathrm{~kg} / \mathrm{m}^{2}$ excesso de peso, de acordo com a classificação de Lipschitz?

\section{DADOS DiETÉtICOS}

Para a obtenção dos dados dietéticos, utilizou-se, pelo mesmo pesquisador, o questionário de freqüência de consumo alimentar semiquantitativo e o recordatório de 24 horas $^{10}$.

As freqüências dos alimentos ingeridos foram obtidas através do consumo realizado diariamente, semanalmente, mensalmente, raramente ou nunca, relatado pelos próprios pacientes e analisadas juntamente com o recordatório de 24 horas para possibilitar melhor a determinação do padrão alimentar individual ${ }^{11}$. Informações sobre o uso de condimentos (artificial, natural e misto) também foram registradas e analisadas.

Os resultados foram descritos qualitativamente através da freqüência de consumo dos itens alimentares, por intermédio da distribuição dos grupos de alimentos e gramatura proporcional (Quadro 1) ${ }^{12,13}$, bem como do recordatório de 24 horas $^{10}$.

Todas as medidas caseiras foram convertidas em gramas e mililitros $(\mathrm{mL})$ de acordo com a Tabela para Avaliação de Consumo Alimentar em Medidas Caseiras ${ }^{14}$ e a Tabela de Composição Química dos Alimentos ${ }^{15}$ e, posteriormente, os grupos alimentares foram analisados e comparados com o Guia Alimentar para a População Brasileira $^{13}$ e com a Pirâmide Alimentar Adaptada para a População Brasileira ${ }^{12}$.

Quadro 1. Exemplos de equivalentes de porções dos alimentos

\begin{tabular}{|c|c|c|c|c|c|}
\hline Alimentos & Peso (g) & Medida caseira & Alimentos & Peso (g) & Medida caseira \\
\hline \multicolumn{6}{|c|}{ Cereais, pães, raízes e tubérculos - 1 porção $=150 \mathrm{kcal}$ (média) } \\
\hline Arroz branco cozido & 125 & 4 colheres (sopa) & Macarrão & 105 & $31 / 2$ colheres (sopa) \\
\hline Batata frita & 50 & 2 colheres de servir & Pão francês & 50 & 1 unidade \\
\hline \multicolumn{6}{|c|}{ Hortaliças - 1 porção $=15 \mathrm{kcal}$ (média) } \\
\hline Alface & 120 & 15 folhas & Jiló & 40 & $1 \frac{1}{2}$ colher (sopa) \\
\hline Cenoura & 36 & 1 colher de servir & Tomate & 80 & 4 fatias \\
\hline \multicolumn{6}{|c|}{ Frutas -1 porção $=70 \mathrm{kcal}$ (média) } \\
\hline Banana & 86 & 1 unidade & Melancia & 230 & 2 fatias \\
\hline Maçã & 130 & 1 unidade & Uva & 99,20 & 22 uvas \\
\hline \multicolumn{6}{|c|}{ Feijões -1 porção $=55 \mathrm{kcal}$ (média) } \\
\hline Feijão com caldo & 86 & 1 concha & Lentilha & 48 & 2 colheres (sopa) \\
\hline Feijão (somente grãos) & 50 & 2 colheres (sopa) & Soja & 43 & 1 colher de servir \\
\hline \multicolumn{6}{|c|}{ Carnes e ovos - 1 porção = 190kcal (média) } \\
\hline Bife de fígado & 100 & 1 unidade média & Frango grelhado & 100 & 1 unidade \\
\hline Carne moída & 90 & 5 colheres (sopa) & Ovo frito & 50 & 1 unidade \\
\hline \multicolumn{6}{|c|}{ Leite e derivados - 1 porção = 120kcal (média) } \\
\hline logurte integral & 200 & 1 copo requeijão & Queijo tipo minas & 50 & $11 / 2$ fatia \\
\hline Leite em pó desnatado & 30 & 2 colheres (sopa) & Queijo prato & 40 & 2 fatias \\
\hline \multicolumn{6}{|c|}{ Óleos e gorduras - 1 porção = 73kcal (média) } \\
\hline Azeite de oliva & 7,60 & 1 colher (sopa) & Manteiga & 9,80 & $1 / 2$ colher (sopa) \\
\hline Margarina vegetal & 9,80 & $1 / 2$ colher (sopa) & Óleo vegetal & 8 & 1 colher (sopa) \\
\hline \multicolumn{6}{|c|}{ Açúcares e doces - 1 porção = 110 kcal (média) } \\
\hline Açúcar cristal & 28 & 1 colher (sopa) & Doce de mamão & 80 & 2 colheres (sopa) \\
\hline Mel & 37,50 & $21 / 2$ colheres (sopa) & Goiabada & 45 & $1 / 2$ fatia \\
\hline
\end{tabular}

Fonte: Adaptado de Philippi et al. ${ }^{12}$ e Ministério da Saúde ${ }^{13}$ 
O Guia Alimentar para a População Brasileira ${ }^{13}$ se baseia nas seguintes orientações diárias para a ingestão dos alimentos: seis porções de cereais, tubérculos e raízes; três porções de frutas; três porções de verduras e legumes; uma porção de leguminosas; três porções de leite e derivados; uma porção de carne, peixe ou ovos; uma porção de óleos e gorduras; uma porção de açúcares e doces; mínimo de 2 litros de água e máximo de duas xícaras de café.

A Pirâmide Alimentar Adaptada ${ }^{12}$ se baseia nos seguintes grupos alimentares e porções: cereais, pães, tubérculos e raízes - cinco a nove porçôes; hortaliças quatro a cinco porçôes; frutas - três a cinco porções; carne e ovos - uma a duas porçôes; leguminosas - uma porção; leite e produtos lácteos - três porçôes; óleos e gorduras uma a duas porçôes; açúcares e doces - uma a duas porções.

Para fins de comparação, a quantidade em gramas (ou $\mathrm{mL}$ ) de cada alimento consumido pelos pacientes foi dividida pela gramatura (ou $\mathrm{mL}$ ) de sua respectiva porção, sendo que cada grupo alimentar foi calculado a partir do somatório da porção de cada alimento relativo aos grupos de alimentos. Calculou-se a gramatura proporcional a partir da divisão da quantidade de alimentos consumidos pela gramatura de sua respectiva porção e, posteriormente, pela gramatura total do seu grupo alimentar correspondente.

\section{OUTROS DADOS DOS HÁBITOS DE VIDA}

Outros dados relacionados aos hábitos de vida como a prática de atividade física, tabagismo e etilismo também foram coletados e analisados. Foram considerados os pacientes que realizavam algum tipo de atividade física pelo menos uma vez por semana, por no mínimo 30 minutos. Em relação ao tabagismo, os pacientes foram classificados como fumantes, exfumantes e não-fumantes; e, em relação ao etilismo, foram caracterizados como etilistas e não-etilistas.

\section{ANÁLISE ESTATÍSTICA}

Todos os dados coletados foram analisados estatisticamente, utilizando-se o programa Epi Info 2004 para Windows, versão 3.3.2. A análise bivariada foi aplicada considerando-se as variáveis: idade e tabagismo; ingestão de bebida alcoólica e tabagismo; café e tabagismo; atividade física e tabagismo.

\section{RESULTADOS}

Os pacientes acompanhados $(\mathrm{n}=70)$ tinham média de idade de 58,30 anos, sendo 47,10\% com 60 anos ou mais (Tabela 1). Quanto ao gênero, 60\% $(n=42)$ eram do sexo feminino e $40 \%(n=28)$ do sexo masculino (Tabela 1).
Observou-se que 45,71\% dos pacientes $(n=32)$ tinham o índice de massa corporal dentro da faixa de eutrofia (IMC $\geq 18,5 \mathrm{~kg} / \mathrm{m}^{2}$ e $\left.<25 \mathrm{~kg} / \mathrm{m}^{2}\right), 35,71 \%(\mathrm{n}=25)$ na faixa de sobrepeso (IMC $\geq 25 \mathrm{~kg} / \mathrm{m}^{2}$ e $<30 \mathrm{~kg} / \mathrm{m}^{2}$ ), $12,86 \%(\mathrm{n}=9)$ na faixa de obesidade $\left(\geq 30 \mathrm{~kg} / \mathrm{m}^{2}\right)$, e apenas $5,71 \%(\mathrm{n}=4)$ na faixa de magreza $\left(<18,5 \mathrm{~kg} / \mathrm{m}^{2}\right)$ (Tabela 1). Analisando-se os pacientes adultos ( $\geq 20$ anos e $<60$ anos, $n=36)$ separadamente, 5,60\% ( $n=2)$ deles apresentavam IMC dentro da faixa de baixo peso; $50 \%$ $(n=18)$ estavam na faixa de eutrofia; 36,10\% ( $n=13)$ na faixa de sobrepeso; e $8,30 \%(n=3)$ na faixa de obesidade. Já os pacientes idosos (60 anos ou mais, $n=34$ ), quando analisados em uma categoria de IMC específica para essa faixa etária, de acordo com Lipschitz ${ }^{9}$, apresentaram-se na faixa de excesso de peso (IMC $\geq 27 \mathrm{~kg}$ / $\left.\mathrm{m}^{2}\right)$ 47,10\% ( $\left.\mathrm{n}=16\right)$; na faixa de eutrofia (IMC $\geq 22 \mathrm{~kg}$ / $\mathrm{m}^{2}$ e $\left.<27 \mathrm{~kg} / \mathrm{m}^{2}\right) 20,60 \%(\mathrm{n}=7)$; e na faixa de baixo peso $\left(\right.$ IMC $\left.<22 \mathrm{~kg} / \mathrm{m}^{2}\right) 32,30 \%(\mathrm{n}=11)$ (Tabela 2$)$.

A prática de atividade física era realizada por $71,43 \%$ $(\mathrm{n}=50)$ dos pacientes, pelo menos uma vez por semana (Tabela 1). Eram tabagistas $8,60 \%(n=6)$, não-tabagistas $67,10 \%(n=47)$ e ex-tabagistas 24,30\% ( $n=17)$ (Tabela 1). Os pacientes tabagistas estavam na faixa etária de 45-80 anos de idade ( $>45$ anos e $<60$ anos, $50 \%, n=3$; e $\geq 60$ anos, $50 \%, n=3$ ) (Tabela 3). Faziam uso de bebidas alcoólicas, 11,40\% (n=8) (Tabela 1). Não foi observada relação entre tabagismo e consumo de bebida alcoólica, sendo que 66,67\% ( $n=4)$ dos pacientes tabagistas negaram consumo de bebida alcoólica; entre os extabagistas, 94,20\% $(n=16)$ também negaram o consumo (Tabela 3). Observou-se que o tabagismo estava associado ao sedentarismo, uma vez que $66,70 \%(n=4)$ dos fumantes não praticavam atividade física (Tabela 3 ). Neste estudo não foram questionadas a quantidade de cigarros/dia nem a quantidade e/ou freqüência da ingestão de bebidas alcoólicas.

Com relação aos hábitos alimentares, foi observado que $87,10 \%(n=61)$ dos pacientes consumiam de cinco a nove porções por dia de cereais, pães, raízes e tubérculos, conforme recomendado pela pirâmide alimentar $^{12}$ (Tabela 4).

Quanto ao consumo diário de frutas, 64,30\% ( $n=45)$ dos pacientes consumiam de uma a duas porções e $7,10 \%(n=5)$ de três a cinco porções, conforme o preconizado pela pirâmide alimentar ${ }^{12}$, totalizando $91,40 \%(n=64)$ que tinham um consumo inferior ao recomendado (Tabela 4).

Com relação às hortaliças, 97,10\% $(\mathrm{n}=68)$ dos pacientes consumiam menos de quatro porções por dia e 2,90\% ( $n=2)$ consumiam de quatro a cinco porçóes diariamente, conforme o recomendado pela pirâmide alimentar $^{12}$ (Tabela 4). 
Tabela 1. Características demográficas dos pacientes entrevistados $(n=70)$

\begin{tabular}{|c|c|c|c|}
\hline Características & $\begin{array}{l}\text { Número de } \\
\text { Pacientes }\end{array}$ & $\begin{array}{l}\text { Freqüência Relativa } \\
\qquad(\%)\end{array}$ & $\begin{array}{l}\text { Freqüência Acumulada } \\
(\%)\end{array}$ \\
\hline \multicolumn{4}{|l|}{ Sexo } \\
\hline Feminino & 42 & 60 & 60 \\
\hline Masculino & 28 & 40 & 100 \\
\hline \multicolumn{4}{|l|}{ Faixa etária } \\
\hline$\leq 30$ anos & 3 & 4,30 & 4,30 \\
\hline$>30 a \leq 45$ anos & 7 & 10 & 14,30 \\
\hline$>45 a<60$ anos & 26 & 37,14 & 51,44 \\
\hline$\geq 60 \mathrm{a} \leq 80$ anos & 34 & 47,10 & 100 \\
\hline \multicolumn{4}{|l|}{ IMC1 $\left(\mathbf{k g} / \mathbf{m}^{2}\right)$} \\
\hline Magreza $(<18,5)$ & 4 & 5,71 & 5,71 \\
\hline Eutrofia $(\geq 18,5 a<25)$ & 32 & 45,71 & 51,42 \\
\hline Sobrepeso $(\geq 25 a<30)$ & 25 & 35,71 & 87,13 \\
\hline Obesidade $(\geq 30)$ & 9 & 12,86 & 100 \\
\hline \multicolumn{4}{|l|}{ Prática de atividade física } \\
\hline Pratica atividade física & 50 & 71,43 & 71,43 \\
\hline Sedentário & 20 & 28,57 & 100 \\
\hline \multicolumn{4}{|l|}{ Tabagismo } \\
\hline Nunca fumou & 47 & 67,10 & 67,10 \\
\hline Ex-tabagista & 17 & 24,30 & 91,40 \\
\hline Tabagista & 6 & 8,60 & 100 \\
\hline \multicolumn{4}{|l|}{ Ingere bebida alcoólica } \\
\hline Não ingere & 62 & 88,60 & 88,60 \\
\hline Ingere & 8 & 11,40 & 100 \\
\hline
\end{tabular}

IMC=índice de massa corporal

Tabela 2. Relação IMC e idade, para idosos $(n=34)$

\begin{tabular}{cccc}
\hline & \multicolumn{3}{c}{ IMC $\left(\mathbf{k g} / \mathbf{m}^{2}\right)$} \\
\hline Faixa etária $^{~}$ & $<22$ & $\geq 22$ a $<27$ & $\geq 27$ \\
& $\mathrm{n}(\%)$ & $3(\%)$ & $\mathrm{n}(\%)$ \\
\hline 260 e $<65$ anos & $3(8,80)$ & - & $2(5,90)$ \\
$\geq 65$ e $<70$ anos & $3(8,80)$ & $4(11,80)$ & $3(8,80)$ \\
$\geq 70$ e $\leq 80$ anos & $5(14,70)$ & $7(20,60)$ & $11(32,30)$ \\
\hline Total & $11(32,30)$ & & $16(47,10)$ \\
\hline
\end{tabular}

Foi averiguado que $61,40 \%(\mathrm{n}=43)$ dos pacientes consumiam menos de uma porção por dia de leguminosas; $28,60 \%(n=20)$ consumiam uma porção conforme recomendado ${ }^{12}, 8,60 \%(n=6)$ consumiam uma porção e meia ou mais de leguminosas e 1,40\% $(n=1)$ dos pacientes não consumiam esse grupo de alimentos (Tabela 4).

O consumo de leite e derivados era realizado por 97,10\% ( $\mathrm{n}=68)$ dos entrevistados. Destes, 75,70\% $(\mathrm{n}=53)$ consumiam uma a duas porçōes; $15,70 \%(\mathrm{n}=11)$ consumiam em média três porçōes por dia, conforme recomendado pela pirâmide ${ }^{12}$, e 5,90\% $(n=4)$ consumiam 
Tabela 3. Relação entre faixa etária, bebida alcoólica, consumo de café, prática de atividade física e tabagismo

\begin{tabular}{l|ccc}
\multicolumn{1}{c|}{ Variáveis } & $\begin{array}{c}\text { Tabagistas } \\
\mathbf{n}(\%)\end{array}$ & $\begin{array}{c}\text { Não-tabagistas } \\
\mathbf{n}(\%)\end{array}$ & $\begin{array}{c}\text { Ex-tabagistas } \\
\mathbf{n}(\%)\end{array}$ \\
\hline $\begin{array}{l}\text { Faixa etária } \\
\leq 30 \text { anos }\end{array}$ & 0 & $3(6,40)$ & 0 \\
$>30$ a $\leq 45$ anos & 0 & $3(6,40)$ & $4(23,50)$ \\
$>45$ a <60 anos & $3(50)$ & $18(38,30)$ & $6(35,30)$ \\
$\geq 60$ a $\leq 80$ anos & $3(50)$ & $23(48,90)$ & $7(41,20)$ \\
Consumo de bebida alcoólica & & & $1(5,80)$ \\
Sim & $2(33,33 \%)$ & $5(10,60)$ & $16(94,20)$ \\
Não & $4(66,67 \%)$ & $42(89,40)$ & $2(13,30)$ \\
Consumo de café & $1(20)$ & $8(18,10)$ & $9(60)$ \\
$<1$ xícara & $1(20)$ & $22(50)$ & $3(20)$ \\
1 a 2 xícaras & 0 & $5(11,40)$ & $1(6,70)$ \\
3 a 4 xícaras & $3(60)$ & $9(20,50)$ & $12(70,60)$ \\
$>4$ xícaras & & & $5(29,40)$ \\
Prática de atividade física & $2(33,30)$ & $36(76,60)$ & $11(23,40)$ \\
Sim & $4(66,70)$ & & \\
Náo & & & \\
\hline
\end{tabular}

Tabela 4. Consumo dos grupos alimentares dos entrevistados por dia

\begin{tabular}{|c|c|c|c|c|}
\hline \multirow[b]{2}{*}{ Grupos alimentares } & \multicolumn{4}{|c|}{ Consumo por parte dos pacientes entrevistados } \\
\hline & $\begin{array}{c}\text { Não consome } \\
\text { n (\%) }\end{array}$ & $\begin{array}{c}\text { Menos que VR } \\
\text { n (\%) }\end{array}$ & $\begin{array}{l}\text { VR* } \\
\text { n (\%) }\end{array}$ & $\begin{array}{c}\text { Mais que VR } \\
\text { n (\%) }\end{array}$ \\
\hline $\begin{array}{l}\text { Cereais, pães, tubérculos e raízes } \\
\text { (5 a } 9 \text { porções/dia) })^{12}\end{array}$ & - & $1(1,40)$ & $61(87,10)$ & $8(11,40 \%)$ \\
\hline $\begin{array}{l}\text { a) Arroz, macarrão, farofa, purê, batata, } \\
\text { inhame, pirão (...) }\end{array}$ & - & $55(78,50)$ & $14(20)$ & $1(1,40)$ \\
\hline b) Pão, bolo, cuscuz, beiju (...) & - & $68(97,10)$ & $2(2,90)$ & - \\
\hline Frutas (3 a 5 porções/dia) ${ }^{12}$ & - & $64(91,40)$ & $5(7,10)$ & $1(1,40)$ \\
\hline Hortaliças (4 a 5 porções/dia) ${ }^{12}$ & - & $68(97,10)$ & $2(2,90)$ & - \\
\hline Leguminosas ( 1 porção/dia) ${ }^{12}$ & $1(1,40)$ & $43(61,40)$ & $20(28,60)$ & $6(8,60)$ \\
\hline Leite e derivados ( 3 porções/dia) ${ }^{12}$ & $2(2,90)$ & $53(75,70)$ & $11(15,70)$ & $4(5,70)$ \\
\hline $\begin{array}{l}\text { Carne, frango, peixe e ovos } \\
(1 \text { a } 2 \text { porções/dia })^{12}\end{array}$ & - & $1(1,40)$ & $43(61,40)$ & $26(37,10)$ \\
\hline Fibras $(\geq 25 \mathrm{~g} / \mathrm{dia})^{13}$ & - & $64(91,40)$ & $6(8,60)$ & - \\
\hline $\begin{array}{l}\text { Doces e açúcares } \\
\left(1 \text { a } 2 \text { porções/dia) }{ }^{12}\right.\end{array}$ & $7(10)$ & $37(52,90)$ & $22(31,40)$ & $4(5,70)$ \\
\hline Café ( $\leq x i ́ c a r a s / d i a)^{13}$ & $6(8,60)$ & - & $43(61,40)$ & $21(30)$ \\
\hline Água $(\geq 2000 \mathrm{~mL} / \mathrm{dia})^{13}$ & - & $62(88,60)$ & $8(11,40)$ & - \\
\hline
\end{tabular}

*VR=valor de referência

mais de três porçôes de leite e derivados por dia (Tabela 4). Ao se analisar a qualidade do leite e derivados, constatou-se que 32,40\% $(n=22)$ dos pacientes consumiam os produtos desnatados e $67,60 \% \quad(n=46)$ faziam uso dos produtos lácteos integrais.

O consumo de carnes e ovos era feito por todos os pacientes, sendo que $61,40 \%(n=43)$ consumiam de uma a duas porções conforme recomendado pela pirâmide alimentar $^{12}$ (Tabela 4). Ao se analisar a qualidade dos produtos cárneos, foi constatado que 54,30\% ( $\mathrm{n}=38)$ dos pacientes consumiam carne bovina; $37,10 \%(n=26)$ frango; $5,70 \%(n=4)$ ovos e $2,90 \%(n=2)$ peixe. Nenhum 
paciente referiu fazer uso de carne suína.

Com relação ao consumo de fibras, $91,40 \%(n=64)$ consumiam menos que $25 \mathrm{~g} / \mathrm{dia}$ conforme recomendado pelo guia alimentar ${ }^{13}$ e $8,60 \%(\mathrm{n}=6)$ consumiam $25 \mathrm{~g} /$ dia de fibras.

Quanto ao consumo de doces e açúcares, $10 \%(\mathrm{n}=7)$ negaram o consumo; $52,90 \%(\mathrm{n}=37)$ consumiam menos de uma porção; $31,40 \%(n=22)$ consumiam de uma a duas porçôes por dia, conforme recomendado pela pirâmide alimentar ${ }^{12}$ e $5,70 \%(\mathrm{n}=4)$ consumiam mais de duas porções diárias (Tabela 4).

Foi observado que a quantidade de água consumida pelos entrevistados era inferior a $500 \mathrm{~mL}$ por dia em $5,80 \%(\mathrm{n}=4)$ dos casos; de $500 \mathrm{~mL}$ a $1000 \mathrm{~mL}$ por dia em $47,10 \%(\mathrm{n}=33)$; de $1000 \mathrm{~mL}$ a $2000 \mathrm{~mL}$ em $35,70 \%$ $(\mathrm{n}=25)$ e de $2000 \mathrm{~mL}$ ou mais, conforme recomendado pelo guia alimentar ${ }^{13}$, em 11,40\% $(\mathrm{n}=8)$ (Tabela 4).

O café era consumido por $91,40 \%(n=64)$ dos pacientes; destes, $15,70 \%(\mathrm{n}=11)$ consumiam menos de uma xícara por dia e $45,70 \%(\mathrm{n}=32)$ consumiam de uma a duas xícaras por dia, conforme recomendado pelo guia alimentar ${ }^{13} ; 11,40 \%(\mathrm{n}=8)$ consumiam de três a quatro xícaras; e $18,60 \%(n=13)$ consumiam mais de quatro xícaras de café por dia (Tabela 4). A faixa etária de 45-60 anos é a que consumia mais café, sendo que $95,60 \%(\mathrm{n}=25)$ consumiam diariamente no mínimo uma xícara de café, seguida da faixa etária dos idosos em que $87,90 \%(n=29)$ consumiam no mínimo uma xícara. O tabagismo também estava associado a um consumo maior de café, sendo que $60 \%(n=3)$ dos fumantes consumiam mais de quatro xícaras de café por dia (Tabela 3).

Quando questionados sobre o preparo dos alimentos, $95,70 \%(\mathrm{n}=67)$ dos pacientes afirmaram usar algum tipo de gordura, sendo que $72,85 \%$ ( $n=51)$ usavam somente gordura vegetal; $22,85 \%(n=16)$, gordura animal; e $4,30 \%(n=3)$ dos pacientes negaram o consumo de qualquer tipo de gordura. Com relação aos condimentos, $12,90 \%(\mathrm{n}=9)$ usavam condimentos industrializados, $72,90 \%(\mathrm{n}=51)$ usavam condimentos naturais, $12,90 \%$ $(\mathrm{n}=9)$ usavam ambos e $1,40 \%(\mathrm{n}=1)$ não utilizavam condimentos para o preparo das refeições.

\section{DISCUSSÃO}

Os dados antropométricos obtidos neste estudo indicaram prevalência de eutrofia $(45,71 \%)$, sobrepeso $(35,71 \%)$ e obesidade $(12,86 \%)$ em portadores de câncer colorretal. De acordo com a literatura, esses achados são plausíveis, uma vez que não é freqüente a desnutrição no câncer de cólon e reto ${ }^{16}$. Isto pode ser explicado devido ao menor comprometimento da ingestão alimentar, ausência de distúrbios nutricionais absortivos, alterações metabólicas mínimas e inexistência de fatores obstrutivos ou efeito hormonal para a caquexia por esta neoplasia.

Estudos científicos têm demonstrado uma associação positiva entre sobrepeso, obesidade e risco de desenvolvimento de diversos tipos de câncer, como também na mortalidade por essa doença ${ }^{17,18}$. Acreditase que o provável mecanismo esteja relacionado à hiperinsulinemia e ao alto nível do fator de crescimento dependente de insulina (IGF-1) e proteínas que se ligam ao IGF-1 (IGFBP), além de dietas caracterizadas pelo consumo excessivo de energia ${ }^{19}$. Comparados com indivíduos de peso normal, os homens com $40 \%$ ou mais de excesso de peso apresentaram índice de mortalidade de 1,33 para todos os tipos de câncer, e entre as mulheres esse índice foi de 1,55. Há uma maior associação entre o excesso de peso e o risco de câncer colorretal em homens quando comparado com as mulheres, sugerindo que a distribuição abdominal ou central de adiposidade corpórea (tipicamente masculina) é o principal componente do aumento desse risco, uma vez que está associada fortemente com a resistência à insulina e à hiperinsulinemia ${ }^{20}$.

De acordo com DeMarini ${ }^{21}$, a dieta é a principal fonte de exposição humana para os carcinógenos/ mutágenos e anticarcinógenos/antimutágenos ambientais, sendo que alguns tipos de câncer associados à alimentação, assim como algumas intervençôes dietéticas, podem reduzir os biomarcadores ou a incidência das neoplasias.

No presente estudo, foi constatado que $87,10 \%$ dos pacientes consumiam de cinco a nove porçōes por dia de cereais, pães, raízes e tubérculos, e que $31,40 \%$ consumiam de uma a duas porçôes por dia de doces e açúcares, conforme recomendado pela pirâmide alimentar $^{12}$.

Os carboidratos complexos diminuem o risco de câncer colorretal, porém seu efeito protetor pode ser atenuado se a maior parte do amido da dieta for refinado. Dietas ricas em carboidratos refinados tendem a ser pobres em fibras, hortaliças, frutas e outros alimentos que exercem efeito protetor contra o câncer colorretal, reforçando a idéia de que principalmente a qualidade glicídica será o fator-chave na sua relação com o câncer ${ }^{22}$, o que pode ser confirmado através de estudos experimentais, epidemiológicos e clínicos que comprovam a relação da carcinogênese com o consumo excessivo de alimentos ricos em carboidratos simples e refinados e pobre em fibras ${ }^{23,24}$.

Os pacientes, neste estudo, não apresentavam ingestão adequada de hortaliças e frutas, sendo que $97,10 \%$ e $91,40 \%$, respectivamente, tinham uma 
ingestão diária inferior às recomendações tanto da pirâmide alimentar ${ }^{12}$ quanto do guia alimentar para a população brasileira ${ }^{13}$.

Estudos científicos têm comprovado o efeito protetor de algumas hortaliças como brócolis, repolho, couve-flor e couve-de-bruxelas, no câncer colorretal. Estas hortaliças contêm substâncias químicas, indóis e isotiocianatos, capazes de estimular enzimas de destoxificação ou redutoras da atividade de enzimas hepáticas que convertem compostos químicos ambientais em potentes carcinógenos, aumentando a solubilidade aquosa de toxinas corpóreas e sua conseqüente eliminação ${ }^{25,26}$.

Estudos de caso-controle comprovam que há uma relação inversa entre a diversidade dietética através do aumento da ingestão de hortaliças e frutas e o risco de desenvolvimento de câncer colorretal, demonstrando que esses alimentos exercem um papel crucial na etiologia dessa neoplasia ${ }^{27-29}$. Porém, ainda não está esclarecido na literatura qual é o determinante anticarcinogênico das frutas e hortaliças, uma vez que as mesmas são fontes de vitaminas, minerais, fibras, fitoquímicos, $\beta$-caroteno, ácido linoléico conjugado, genisteína, indóis, isotiocianatos, flavonóides, dentre outras substâncias que exercem efeito protetor contra o câncer ${ }^{6,21}$.

Em relação à ingestão de fibras, $91,40 \%$ dos pacientes consumiam menos do que $25 \mathrm{~g} / \mathrm{dia}$ e apenas $8,60 \%$ apresentavam adequada ingestão $(\geq 25 \mathrm{~g} / \mathrm{dia})$ de acordo com o guia alimentar para a população brasileira ${ }^{13}$.

Outro estudo de caso-controle foi conduzido em pacientes com câncer de cólon e reto com o intuito de investigar os hábitos dietéticos, particularmente a ingestão de fibras, através da utilização do questionário de freqüência alimentar semiquantitativo. Os resultados obtidos demonstraram a existência de uma relação inversa entre o consumo de fibras e o risco de câncer colorretal ${ }^{30}$.

Evidências científicas têm demonstrado que a carência de fibras na dieta eleva o tempo de trânsito intestinal, aumentando a concentração do conteúdo luminal, propiciando um maior contato de agentes nocivos e carcinógenos com a mucosa colônica. Dentre esses agentes, destacam-se os sais biliares, metabólitos de ácidos graxos de cadeia curta, gerados pelo aumento do $\mathrm{pH}$ intraluminal com dietas pobres em fibras, que são formados pelo metabolismo de gorduras e proteínas animais, determinando alterações epiteliais importantes, podendo culminar com o desenvolvimento dos cânceres de cólon e reto ${ }^{25,31}$.

Por outro lado, estudos comprovam que o aumento das fibras na dieta promove incremento nas concentrações de ácidos graxos de cadeia curta formados pela fermentação de bactérias colônicas, desempenhando conseqüentemente importante papel no metabolismo intestinal. Dentre os efeitos dos ácidos graxos de cadeia, destacam-se a indução da diferenciação de linhagens celulares, trofismo sobre o epitélio atrófico, inibição do crescimento e desenvolvimento do epitélio hiperproliferativo e ação celular anticarcinogênica ${ }^{25,26,31}$. Acredita-se que a principal atuação dos ácidos graxos de cadeia curta se deve à ação do butirato ${ }^{32}$ no controle e na promoção da diferenciação celular, apoptose e supressão de células neoplásticas ${ }^{33}$, através da regulação de vários oncogenes e indução de hiperacetilação de histonas ${ }^{34}$. Além disso, as fibras podem reduzir os níveis glicêmicos e melhorar a resistência à insulina, influenciando positivamente no IGF-1 que é um promotor do processo de carcinogênese colorretal ${ }^{30}$.

Da mesma forma que as hortaliças e frutas, alguns aspectos da relação inversa entre as fibras e o câncer colorretal não estão completamente elucidados na literatura, uma vez que as fibras possuem em sua composição diversos componentes potencialmente benéficos como vitaminas, antioxidantes, flavonóides, entre outras substâncias que influenciam favoravelmente no processo de carcinogênese $\mathrm{e}^{30}$.

Em relação às leguminosas, foi averiguado neste estudo que $61,40 \%$ dos pacientes consumiam, diariamente, menos de uma porção; $8,60 \%$, uma porção e meia ou mais; e $28,60 \%$ consumiam uma porção por dia, conforme recomendado pela pirâmide alimentar ${ }^{12}$. Apenas um paciente $(1,40 \%)$ referiu não consumir esse grupo de alimentos, pois constantemente apresentava diarréia, fazia uso da bolsa de colostomia, sentia grande fobia ao consumo de leguminosas, além de seguir a recomendação médica de não usar esse grupo de alimentos.

O consumo regular de leguminosas é imprescindível devido ao seu efeito benéfico para a saúde, promovendo a redução de diversas doenças como o câncer ${ }^{35}$. $\mathrm{Na}$ literatura, a relação entre o câncer colorretal e as leguminosas não está completamente elucidada e estudos epidemiológicos demonstram efeitos contraditórios ${ }^{22}$. Entretanto as leguminosas contêm carboidratos complexos, proteínas de origem vegetal, fibras, fitoquímicos, minerais como o cálcio, ferro, potássio, zinco e manganês e substâncias bioativas que exercem diversos efeitos protetores contra o câncer ${ }^{13}$.

O consumo de carnes e/ou ovos foi realizado por $61,40 \%$ dos pacientes na quantidade de uma a duas porções conforme recomendado pela pirâmide alimentar ${ }^{12}$. Em relação à qualidade dos produtos cárneos, foi constatado que $54,30 \%$ dos pacientes consumiam carne vermelha, e 5,70\% consumiam ovos.

$\mathrm{Na}$ literatura, não há consenso quanto à relação entre o consumo de carne e seus derivados e o desenvolvimento de câncer colorretal ${ }^{36}$. Evidências epidemiológicas 
sugerem que dietas com alto teor de carne vermelha ${ }^{6,22} \mathrm{e}$ de gordura, associadas a um baixo teor de carboidratos fermentados como as fibras, aumentam o risco de câncer de cólon. Um dos mecanismos que pode explicar a associação entre o câncer colorretal e a carne vermelha é o aumento do metabolismo de proteínas no cólon. Os produtos finais desse processo metabólico incluem a formação de amônia, fenóis, indóis, nitratos, sulfitos e aminas, que têm demonstrado efeitos tóxicos em estudos in vitro e em modelos animais. Estes compostos estão presentes em amostras fecais, sugerindo um efeito tóxico sobre a mucosa intestinal ${ }^{37}$.

Estudos epidemiológicos indicam que o agente etiológico presente nas carnes não é a gordura total, mas sim o tipo de gordura ou a ingestão energética total. Pesquisas realizadas em laboratórios têm identificado muitos carcinógenos presentes na carne, como as nitrosaminas, hidrocarbonetos aromáticos policíclicos, aminas heterocíclicas, entre outros ${ }^{21}$. Acredita-se que um dos principais mecanismos que pode estar implicado na gênese do câncer colorretal esteja relacionado aos processos de preparo e cocção da carne ${ }^{38}$. Os principais constituintes naturais formados durante o processo de cocção da carne incluem as gorduras, nitratos, nitritos e carcinógenos. Está bem documentado na literatura que os compostos $\mathrm{N}$-nitrosos e o nitrato induzem à formação tumoral por meio da sua transformação em nitrito, culminando com o aumento na produção de radicais livres e lesão celular ${ }^{6,26}$. Observa-se também que o alto consumo de ovos está relacionado a um incremento no risco de desenvolver câncer colorretal ${ }^{36}$, embora o seu consumo, assim como o de carnes brancas, tenha menor impacto na etiologia do câncer ${ }^{22}$.

Somente $15,70 \%$ dos pacientes neste estudo consumiam, em média, três porções de leite e derivados por dia conforme a pirâmide ${ }^{12}$, e o restante consumia um valor inferior às recomendações. Em relação à qualidade dos produtos lácteos, foi observado que $67,60 \%$ dos pacientes faziam uso dos produtos lácteos integrais.

Vários estudos epidemiológicos estão sendo conduzidos para determinar os efeitos do consumo de leite e lacticínios na carcinogênese. Tem sido proposto que a gordura em geral promove carcinogênese, porém a ingestão só do leite conjugado com ácido linoléico pode exercer efeitos inibitórios. Há também evidências consideráveis de que o cálcio do leite protege contra o câncer de cólon. A proteína do soro do leite tem papel benéfico, demonstrado em estudos com animais e humanos. Dados experimentais têm revelado que a lactoferrina bovina inibe a carcinogênese no cólon ${ }^{39}$.

Existe uma relação positiva entre a incidência de câncer de cólon e a média percentual de calorias provenientes das gorduras, tanto para homens quanto para mulheres ${ }^{40}$. O World Cancer Research Fund e American Institute for Cancer Research sugerem haver evidências consistentes de que dietas ricas em gorduras possam aumentar o risco de câncer colorretal ${ }^{22,25}$. O papel das gorduras na carcinogênese pode variar de acordo com a sua origem e composição ${ }^{6,41}$. Acredita-se que a elevada ingestão de gordura total promove aumento na produção de ácidos biliares, que são mutagênicos e citotóxicos ${ }^{22}$.

Um total de $4,30 \%$ dos pacientes negou consumo ou referiu redução importante no consumo de gorduras após a realização do diagnóstico; porém 72,90\% dos pacientes informaram a utilização de gordura vegetal no preparo dos alimentos. Alguns componentes desse tipo de gordura estão implicados no desenvolvimento de câncer colorretal ${ }^{32}$.

A associação com câncer colorretal e ácidos graxos de cadeia média (AGCM) como o láurico (leite de coco e chocolate) e miriástico (coco) tem sido pouco estudada $^{32}$. Alguns estudos demonstram que ambos tenham ação a favor dos ácidos ômega-6 (alfa-linoléico $)^{42}$, podendo estar associados a um incremento no risco de desenvolver câncer colorretal ${ }^{32}$.

Doenças crônicas, como o câncer, estão relacionadas ao aumento na produção de tromboxanas, leucotrienos, interleucina-1, interleucina-6, fator de necrose tumoral e proteína C-reativa, devido à resposta imunológica realizada pelo organismo. $\mathrm{O}$ aumento no consumo de ômega- 6 promove elevação desses fatores, enquanto o aumento no consumo de ômega-3 (ácido alfa-linolênico), contido nos peixes, promove a redução dos mesmos ${ }^{43}$. Estudos indicam que as dietas ocidentais são deficientes em ômega-3 e que, nelas, a relação ômega-6/ômega-3 oscila de $15: 1$ a 16,7:1, reconhecendo que a modulação dessa relação para 2,5/1 reduz a proliferação celular retal em pacientes com câncer ${ }^{25}$. Vale destacar que apenas $2,90 \%$ dos pacientes referiram consumo de peixes.

Uma porcentagem de $22,85 \%$ dos pacientes referiu consumo de alimentos preparados com gordura animal. $\mathrm{O}$ ácido miriástico encontra-se presente também nas carnes, contribuindo para o incremento no risco de desenvolver câncer colorretal ${ }^{32}$. A gordura saturada, presente em alimentos de origem animal como o bacon, apresenta um aumento no risco de desenvolver câncer colorretal $^{25}$. Assim, sugere-se que seja feita a substituição de alimentos com alto teor de AGCM e ácido araquidônico por dietas ricas em ácidos graxos de cadeia curta e ácido eicosapentaenóico para reduzir o risco de câncer colorretal ${ }^{25}$.

$\mathrm{O}$ presente estudo constatou que a quantidade de água ingerida pela maioria dos pacientes $(88,60 \%)$ foi inferior às quantidades recomendadas pelo guia alimentar ${ }^{13}$, sendo 
que apenas 11,40\% ingeriam, no mínimo, 2 litros de água, conforme preconizado; $35,70 \%$ apresentavam ingestão diária de $1000 \mathrm{~mL}$ a $2000 \mathrm{~mL}$.

A água desempenha diversas funções orgânicas vitais e imprescindíveis como transporte de gases, alimentos e produtos do metabolismo celular, regulação da temperatura corpórea, dentre outras ${ }^{13}$. Neste estudo, não foi considerada a quantidade de água presente nos alimentos como frutas, hortaliças, cereais etc. Apesar da recomendação de pelo menos 2 litros de água por dia, é sabido que, em determinadas condições clínicas, como idade avançada e carcinoma do trato gastrintestinal, a necessidade de água encontra-se reduzida ${ }^{44}$.

Poucos são os estudos que relacionam a ingestão de água com o câncer colorretal. Dados na literatura comprovam apenas que, dependendo do tratamento utilizado para a água destinada ao consumo humano e das substâncias nela contidas, em longo prazo, poderá haver o desenvolvimento de tipos específicos de câncer $^{45,46}$. Vale enfatizar que uma ingestão adequada de água auxilia nos processos metabólicos orgânicos como um todo ${ }^{13}$.

O café, menos de duas xícaras por dia, era consumido por $61,40 \%$ dos pacientes, conforme recomendado pelo guia alimentar ${ }^{13}$, sendo que $8,60 \%$ referiram não consumir esse tipo de alimento.

Evidências científicas têm sugerido um efeito protetor do consumo de café no risco de desenvolvimento de câncer colorretal. Acredita-se que esse efeito está relacionado às substâncias bioativas presentes no café como flavonóides, entre outros antioxidantes ${ }^{47}$. Na literatura, há controvérsias em relação a essa associação. Dados de cinco estudos que relacionaram o consumo de café com o risco de câncer colorretal demonstraram os seguintes resultados: em três estudos, houve uma ausência de associação; em um estudo, risco aumentado de câncer entre os consumidores de café; e, no outro estudo, associação inversa entre o consumo do café e o risco dessa doença ${ }^{36}$.

Neste estudo, observou-se que $8,60 \%$ dos pacientes entrevistados eram tabagistas, 24,30\%, ex-tabagistas e $67,10 \%$, não tabagistas. Não foi investigada a quantidade de cigarros consumidos por dia e nem o tempo de consumo.

Estudos científicos têm relacionado a incidência de câncer colorretal com dados sobre a quantidade de cigarros/dia e o tempo de vício ${ }^{48-50}$, indicando que tabagistas que consomem cigarros durante muitos anos possuem um risco aumentado para adenoma colorretal e, provavelmente, câncer de cólon ${ }^{49}$, além de elevada mortalidade por essa doença, com conseqüente redução do risco à medida que param de fumar mais cedo ${ }^{51}$.

$\mathrm{O}$ adenoma colorretal, suas características de prevalência, tamanho específico, número de lesões, tipo histológico além da sua localização estão relacionados a um maior risco de câncer ${ }^{52,53}$. Devido à alta prevalência de adenomas, a identificação dos seus fatores de risco pode facilitar o desenvolvimento de estratégias preventivas e de detecção precoce para o câncer colorretal $^{53}$. Entretanto, apesar de os estudos epidemiológicos demonstrarem que o tabagismo está associado com esses pólipos, a relação entre tabagismo e câncer colorretal não está totalmente esclarecida devido, provavelmente, ao longo período de indução ${ }^{48,54}$. Acredita-se que a associação entre tabagismo e câncer colorretal está relacionada ao cariótipo com os alelos CYP1A1 Val $_{462}$ e NQO1 Ser ${ }_{187}$ presente particularmente em fumantes com propensão à formação de lesôes múltiplas ${ }^{55}$, e que essa associação também pode depender das características moleculares tumorais como a mutação de polipose adenomatosa coli (APC) e a expressão do Hmlh1 (human mut-L homologue) ${ }^{56}$.

Em relação ao consumo de bebidas alcoólicas, apenas $11,40 \%$ dos pacientes relataram fazer uso de algum tipo de substância alcoólica. Estudos mostram que o consumo excessivo de álcool é um fator de risco para adenomas e neoplasia colorretal ${ }^{57}$. Entretanto o impacto do consumo na prevenção do câncer e detecção precoce ainda não foi completamente elucidado. Também não está claro se todos os tipos de bebidas alcoólicas estão associados ao aumento do risco ${ }^{58}$. Alguns estudos mostraram associação entre o consumo de cerveja, adenomas e câncer, porém essa associação não foi observada com o consumo de vinho ${ }^{59}$.

Otani et al. ${ }^{60}$ fizeram um estudo prospectivo analisando a associação entre o consumo de bebida alcoólica e tabagismo com o câncer colorretal na população asiática, já que essa é mais susceptível geneticamente aos efeitos dessas substâncias, e chegaram à conclusão de que metade dos casos de câncer poderia ter sido prevenida com o controle do consumo de álcool e tabaco em homens japoneses de meia-idade e idosos. Esses resultados devem ser interpretados com grande cautela, pois muitos desses estudos não levam em consideração a história familiar e dietética.

No presente estudo, a prática de atividade física era realizada por $71,43 \%$ pacientes, pelo menos uma vez por semana. Porém, de acordo com o guia alimentar ${ }^{13}$, recomenda-se que a atividade física seja exercida pelo menos 30 minutos todos os dias. Observou-se também que $66,70 \%$ dos indivíduos que não praticavam atividade física eram tabagistas.

Estudos epidemiológicos indicam que, além de uma dieta variada com elevado consumo de frutas, hortaliças e fibras, baixo consumo de alguns tipos de gordura e 
ingestão calórica moderada, a prática de atividade física está intimamente relacionada ao risco reduzido de diversos tipos de câncer ${ }^{21}$, particularmente, colorretal ${ }^{30}$.

Segundo Shike ${ }^{57}$, a atividade física inadequada está associada ao risco aumentado para o câncer. Acreditase que o principal mecanismo envolvido na redução do risco de câncer colorretal através da prática de atividade física é a capacidade que a mesma exerce na melhoria da resistência à insulina ${ }^{30}$. Porém, ainda não está esclarecido na literatura se a atividade física isoladamente é um fator de risco ou se associada à obesidade propicia um risco aumentado de câncer colorretal, uma vez que exercícios físicos irregulares, geralmente, favorecem o ganho de peso $^{57}$. Outras variáveis também devem ser consideradas, como pessoas que praticam atividade física regular, geralmente, procuram ter uma dieta adequada em todos os princípios nutritivos.

\section{CONCLUSÃO}

Os resultados sugerem a necessidade da monitorização nutricional dos pacientes com câncer colorretal, não somente pela alta freqüência de sobrepeso e obesidade, como também pela inadequação do padrão dietético encontrado. Os benefícios para a redução dos coeficientes de incidência e mortalidade de câncer através das modificações nos hábitos de vida estão amplamente documentados. Mesmo sendo pacientes em fase pósoperatória com acompanhamento médico freqüente, averiguou-se uma ingestão precária da maioria dos fatores protetores contra o câncer colorretal, como dieta pobre em fibras, hortaliças e frutas. Desta forma, tornase imprescindível a realização de programas educacionais multidisciplinares com a atuação de nutricionistas, médicos, educadores físicos, entre outros profissionais da área de saúde, com o intuito de orientar os pacientes na melhoria da qualidade de vida e reforçar os hábitos de vida saudáveis.

\section{REFERÊNCIAS}

1. Instituto Nacional de Câncer. Estimativa 2006: Incidência de câncer no Brasil. Rio de Janeiro: INCA; 2005.

2. Mahayri N, Moreira Filho DC. A importância dos registros de câncer de base populacional para identificar casos de câncer ginecológico relacionados com câncer colorretal em população de risco. Rev Bras Cancerol. 2002;48(3):349-56.

3. Bin FC. Rastreamento para câncer colorretal. Rev Assoc Med Bras. 2002;48(4):275-96.

4. Pinho MSL, Ferreira LC, Brigo MJK, Pereira Filho A, Wengerkievicz A, Ponath A, et al. Incidência do câncer colorretal na região de saúde de Joinville (SC). Rev Bras
Coloproctol. 2003;23(2):73-76.

5. Mallmann ACM, Koshimizu RT, Carvalho LP, Muxfeldt RA. Rastreamento do câncer colorretal. Rev Técnico-Científica do Grupo Hospitalar Conceição. 2003;16(1):13-15.

6. Garófolo A, Avesani CM, Camargo KG, Barros ME, Silva SRJ, Taddei JAAC, et al. Dieta e câncer: um enfoque epidemiológico. Rev Nutr Campinas. 2004;17(4):491-505.

7. Waitzberg DL, Ferrini MT. Exame físico e antropometria. In: Waitzberg DL. Nutrição oral, enteral e parenteral na prática clínica. São Paulo: Atheneu; 2000:255-78.

8. World Health Organization (WHO). Physical status: the use and interpretation of anthropometry. WHO Technical Report Series 854. Geneva: WHO. 1995.

9. Lipschitz DA. Screening for nutritional status in the elderly. Prim Care. 1994;21(1):55-67.

10. Hammond KA. Avaliação dietética e clínica. In: Mahan LK, Escott-stump S. Krause alimentos, nutrição e dietoterapia. São Paulo: Roca; 2002:341-66.

11. Vasconcelos FAG. Avaliação nutricional de coletividades. 3a ed. Florianópolis: UFSC; 2000:116-26.

12. Philippi ST, Latterza AR, Cruz ATR, Ribeiro LC. Pirâmide alimentar adaptada: guia para a escolha dos alimentos. Rev Nutr. 1999;12:65-80.

13. Ministério da Saúde. Guia alimentar para a população brasileira: promovendo a alimentação saudável. Ministério da Saúde, Secretaria de Atenção à Saúde, Coordenação-Geral da Política de Alimentação e Nutrição. Brasília: MS; 2005.

14. Pinheiro ABV. Tabela para avaliação de consumo alimentar em medidas caseiras. 4a ed. Rio de Janeiro: Atheneu; 2000.

15. Franco G. Tabela de composição química dos alimentos. 9a ed. Rio de Janeiro: Atheneu; 2001.

16. Continente AJC, Pluvius CC, Martinez CV. Nutrición y neoplasias digestivas. Rev Bras Nutr Clin. 2002;17:53-63.

17. Bergstrom A, Pisani P, Tenet V, Wolk A, Adami HO. Overweight as an avoidable cause of cancer in Europe. Int J Cancer. 2001;91(3):421-30.

18. Calle EE, Rodriquez C, Walker-Thurmond K, Thun MJ. Overweight, obesity, and mortality from cancer in a prospectively studied cohort of US adults. N Engl J Med. 2003;348(17):1625-638.

19. Augustin LS, Franceschi S, Jenkins DJA, Kendall CWC, Vecchia CLA. Glycemic index in chronic disease: a review. Eur J Clin Nutr. 2002;56:1049-1071.

20. Halpern A, Mancini MC. Obesidade, hiperinsulinismo e câncer In: Waitzberg DL. Dieta, nutrição e câncer. São Paulo: Atheneu; 2004:734-38.

21. DeMarini DM. Dietary interventions of human carcinogenesis. Mutat Res. 1998;400:457-65.

22. World Cancer Research Fund \& American Institute for Cancer Research (WCRF/AICR). Food, nutrition and prevention of cancer: a global perspective. Washington: World Cancer Research Fund \& American Institute for Cancer Research; 1997. 
23. Riboli E, Norat T. Epidemiologic evidence of the protective effect of fruit and vegetables on cancer risk. Am J Clin Nutr. 2003;78(3):559S-69S.

24. Leser SM, Soares EA. Aspectos nutricionais e atividade física na prevenção do câncer colorretal. Nutrire Rev Soc Bras Aliment Nutr. 2001;21:121-45.

25. Campos FG, Waitzberg DL, Habr-Gama A. Influência da dieta na gênese do câncer colorretal. In: Waitzberg DL. Dieta, nutrição e câncer. São Paulo: Atheneu; 2004:247-52.

26. Carneiro MM, Martins MCT, Fraser G. Longevidade e qualidade de vida: a experiência de saúde dos adventistas do sétimo dia e suas aplicações para o Brasil. Rev Nutr Clin. 2005;13(74):12-20.

27. Fernandez E, Negri E, Vecchia CL, Franceschi S. Diet diversity and colorectal cancer. Prev Med. 2000;31:11-14.

28. Slattery ML, Curtin KP, Edwards SL, Schaffer DM. Plant foods, fiber, and rectal cancer. Am J Clin Nutr. 2004;79(2):274-81.

29. Oh SY, Lee JH, Jang DK, Heo SC, Kim HJ. Relationship of nutrients and food to colorectal cancer risk in Koreans. Nutr Res. 2005;25:805-13.

30. Levi F, Pasche C, Lucchini F, Vecchia CL. Dietary fibre and the risk of colorectal cancer. Eur J Cancer. 2001;37:20912096.

31. Ling WH. Diet and colonic microflora interactions in colorectal cancer. Nutr Res. 1995;15(3):439-54.

32. Nkondjock A, Shatenstein B, Maisonneuve P, Ghadirian P. Specific fatty acids and human colorectal cancer: an overview. Cancer Detect Prev. 2003;27:55-66.

33. Lipkin M, Reddy B, Newmark H, Lamprecht SA. Dietary factors in human colorectal cancer. Annu Rev Nutr. 1999; 19:545-86.

34. Rose DP, Connolly JM. Omega-3 fatty acids as cancer chemopreventive agents. Pharmacol Ther. 1999;83:217-44.

35. Leterme P. Recommendations by health organizations for pulse consumption. Br J Nutr. 2002;88(suppl 3): S239-S42.

36. Marques-Vidal P, Ravasco P, Camilo ME. Foodstuffs and colorectal cancer risks: a review. Clin Nutr. 2006;25:14-36.

37. Hughes R, Magee EA, Bingham S. Protein degradation in large intestine: relevance to colorectal cancer. Curr Issues Intest Microbiol. 2000;1(2):51-58.

38. Svensson BG, Mikoczy Z, Stromberg U, Hagmar L. Mortality and cancer incidence among Swedish fishermen with a high dietary intake of persistent organochlorine compounds. Scand J Work Environ Health. 1995;21(2):106-15.

39. Tsuda H, Sekine K, Ushida Y, Kuhara T, Takasuka N, Iigo $\mathrm{M}$, et al. Milk and dairy products in cancer prevention: focus on bovine lactoferrin. Mutat Res. 2000;462(23):227-33.

40. Carrol KK. Nutrition and cancer: fat. In: Rowland IR (ed). Nutrition, toxicity in cancer. Florida: CRC Press; 1991:439-53.
41. Greenwald P, Clifford CK, Milner JA. Diet and cancer prevention. Eur J Cancer. 2001;37(8):948-65.

42. De Decker EAM. Possible beneficial effect of fish and fish n-3 polyunsaturated fatty acids in breast and colorectal cancer. Eur J Cancer Prev. 1999;8(3):213-21.

43. Simopoulos AP. Dossier: Polyunsaturated fatty acids in biology and diseases: the importance of the ratio of omega6/omega-3 essential fatty. Biomed Pharmacother. 2006;56:365-79.

44. Waitzberg DL. Água. In: Waitzberg DL. Nutrição oral, enteral e parenteral na prática clínica. São Paulo: Atheneu; 2000:3-14.

45. Meyer ST. O uso de cloro na desinfecção de águas, a formação de trihalometanos e os riscos potenciais à saúde pública. Cad Saúde Pública. 1994;10(1):99-110.

46. Doyle TJ, Zheng W, Cerhan JR, Hong CP, Sellers TA, Kushi $\mathrm{LH}$, et al. The association of drinking water source and chlorination by-products with cancer incidence among postmenopausal women in Iowa: a prospective cohort study. Am J Public Health. 1997;87(7):1168-176.

47. Machado LMM, Dórea JG, Costa THM. Aspectos econômicos, nutricionais e funcionais do café. Nutrição em Pauta. 2006;14(78):5-10.

48. Stürmer T, Glynn RJ, Lee IM, Christen WG, Hennekens $\mathrm{CH}$. Lifetime cigarette smoking and colorectal cancer incidence in the physicians' health study. J Natl Cancer Inst. 2000;92(14):1178-181.

49. Giovannucci E. An updated review of the epidemiological evidence that cigarette smoking increases risk of colorectal cancer. Cancer Epidemiol. Biomarkers Prev. 2001;10:725-31.

50. Tranah GJ, Giovannucci E, Ma J, Fuchs C, Hankinson SE, Hunter DJ. Epoxide hydrolase polymorphisms, cigarette smoking and risk of colorectal adenoma in the Nurses' Health Study and the Health Professionals Follow-up Study. Carcinogenesis. 2004;25(7):1211-218.

51. Chao A, Thun MJ, Jacobs EJ, Henley SJ, Rodríguez C, Calle EE. Cigarette smoking and colorectal cancer mortality in the cancer prevention study II. J Natl Cancer Inst. 2000;92(23):1888-896.

52. Fearon ER. Genetic alterations underlying colorectal tumorigenesis. Cancer Surv. 1992;12:19-136.

53. Reid ME, Marshall JR, Roe D, Lebowitz M, Alberts D, Battacharyya AK, et al. Smoking exposure as a risk factor for prevalent and recurrent colorectal adenomas. Cancer Epidemiol Biomarkers Prev. 2003;12:1006-1011.

54. Ji BT, Weissfeld JL, Chow WH, Huang WY, Schoen RE, Hayes RB. Tobacco smoking and colorectal hyperplastic and adenomatous polyps. Cancer Epidemiol Biomarkers Prev. 2006;15(5):897-901.

55. Hou L, Chatterjee N, Huang WY, Baccarelli A, Yadavalli S, Yeager M, et al. CYP1A1 Val462 and NQO1 Ser187 polymorphisms, cigarette use, and risk for colorectal adenoma. Carcinogenesis. 2005;26(6):1122-128. 
56. Lüchtenborg M, Weijenberg MP, Kampman E, Van Muijen GN, Roemen GMJM, Zeegers MPA, et al. Cigarette smoking and colorectal cancer: APC mutations, hMLH1 expression, and GSTM1 and GSTT1 polymorphisms. Am J Epidemiol. 2005;161(9):806-15.

57. Shike M. Diet and lifestyle in the prevention of colorectal cancer: an overview. Am J Med. 1999;106(1 suppl A):11-15.

58. Anderson JC, Alpern Z, Sethi G, Messina CR, Martin C, Hubbard PM, et al. Prevalence and risk of colorectal neoplasia in consumers of alcohol in a screening population. Am J Gastroenterol. 2005;100(9):2049-2055.
59. Riboli E, Cornée J, Macquart-Moulin G, Kaaks R, Casagrande C, Guyader M. Cancer and polyps of the colorectum and lifetime consumption of beer and other alcoholic beverages. Am J Epidemiol. 1991:134:157-66.

60. Otani T, Iwasaki M, Yamamoto S, Sobue T, Hanaoka T, Inoue $\mathrm{M}$, et al. Alcohol consumption, smoking, and subsequent risk of colorectal cancer in middle-aged and elderly Japanese men and women: Japan Public Health Center-based prospective study. Cancer Epidemiol Biomarkers Prev. 2003;12:1492-500.

\section{Abstract}

Introduction: Lifestyle can pose multiple risk factors for colorectal cancer, since the interaction between inadequate diet, alcoholism, smoking, obesity, and lack of physical activity can lead to the disease. Objective: To analyze the dietary habits of post-operative colorectal cancer patients. Methodology: Descriptive cross-sectional study. Sample of 70 patients with colorectal cancer treated in the Proctology Clinic, Hospital de Base, Brasilia, Brazil. Anthropometrics and dietary and other lifestyle data were collected. Results: Patients, 28 men and 42 women, presented average age 58,30 years. $71.43 \%$ of patients reported some physical activity. $8.60 \%$ were smokers and $24.30 \%$ former smokers. $11.40 \%$ consumed alcoholic beverages regularly. As for diet: $87.10 \%$ consumed $5-9$ portions/day of cereals, bread, roots, and tubercles; $7.10 \%, 3-5$ portions/day of fruit; $2.90 \%$, 4-5 portions/day of vegetables and legumes; $28.60 \%$, 1 portion/day of beans; $15.70 \%, 3$ portions/day of milk and dairy products; $61.40 \%, 1-2$ portions/day of meat and eggs; $31.40 \%, 1-2$ portions/day of candy and sugar; $8.60 \%, \geq 25 \mathrm{~g} /$ day of food fiber; $11.40 \%, \geq 2$ liters/day of water; $70.00 \%, \leq 2$ cups/day of coffee. When asked about preparation of food, $72.90 \%$ used vegetable oil and $22.90 \%$ used animal fat and vegetable oil; $12.90 \%$ used industrially processed spices, $72.90 \%$ natural spices, and $12.90 \%$ both. Conclusion: The study identified substandard dietary intake of the majority of protective factors against colorectal cancer, highlighting the need for multidisciplinary educational programs to orient patients for improving their quality of life by reinforcing healthy eating habits.

Key words: Diet, Colorectal cancer, Lifestyle 